TURIZAM

Volume 16, Issue 1

8-19 (2012)

\title{
Using Bayesian network and AHP method as a marketing approach tools in defining tourists' preferences
}

\author{
Nataša Papić-Blagojević*, Tamara Gajić*, Nenad Đokićc* \\ Received: September 2011 | Accepted: December 2011
}

\begin{abstract}
Marketing approach is associated to market conditions and achieving long term profitability of a company by satisfying consumers' needs. This approach in tourism does not have to be related only to promoting one touristic destination, but is associated to relation between travel agency and its clients too. It considers that travel agencies adjust their offers to their clients' needs. In that sense, it is important to analyze the behavior of tourists in the earlier periods with consideration of their preferences. Using Bayesian network, it could be graphically displayed the connection between tourists who have similar taste and relationships between them. On the other hand, the analytic hierarchy process (AHP) is used to rank tourist attractions, with also relying on past experience. In this paper we examine possible applications of these two models in tourism in Serbia. The example is hypothetical, but it will serve as a base for future research. Three types of tourism are chosen as a representative in Vojvodina: Cultural, Rural and Business tourism, because they are the bright spot of touristic development in this area. Applied on these forms, analytic hierarchy process has shown its strength in predicting tourists' preferences.
\end{abstract}

Keywords: marketing approach, tourists' preferences, Bayesian network, AHP method

\section{Introduction}

Considering the various ways in which companies have undertaken marketing activities in their orientation toward the market, several competing concepts can be recognized: production concept, product concept, concept of selling, marketing concept as well as the concept of holistic marketing (Kotler, Keller, 2006). Using the marketing concept, instead of the former "produce and sell" philosophy, has led to a movement to the "feel and react" motto aimed at the consumer. This motto arose from the realization that the essence of achieving the companies' goals lies in its greater efficiency in comparison with the competition when

* Higher School of Professional Bussines Studies, Vladimira Perića-Valtera 4, 21000 Novi Sad, Serbia Corresponding author: npapic.blagojevic@gmail.com; tel: +381641736839. 
it comes to the creation, delivery and communication of value to customers in selected target markets. However, the concept of holistic understanding of marketing was added to this concept. Holistic marketing approach have arisen from the needs for a more comprehensive, cohesive approach with which it would be possible to overcome the traditional application of marketing concepts and try to accept and reconcile the scope and complexity of marketing activities (Kotler, Keller, 2006).

In the standard case, application of marketing concept is brought in connection with business operations of companies that try to operate profitably by providing long-term customer satisfaction. However, marketing is characterized by ambiguity (Vasiljev, 2005), so it can be also seen as an economic process, as well as a business function, as a business concept and as a scientific discipline. Previously mentioned observation suggests that considering marketing as a relation between a company and the market does not lit up all the meanings which can be attached to marketing, especially if one bears in mind all the things that are launched in today's market (Kotler, Keller, 2006): goods, services, events, experiences, personalities, places, property, organizations, information as well as ideas.

Like all consumer products, tourist destinations need to convince customers that they have a combination of benefits that no one else can offer. By applying modern marketing techniques, destinations are trying to establish themselves as brands. How tourist destinations become, develop, protect and strengthen their position in the fiercer competition in the global marketplace is an issue that is arose from the tourism industry. Tourist destinations are, by their nature, substantially different from other commercial products and, there so, have its own characteristics (Crouch, 2007).

Destinations and tourists interact and create the tourism experience (Von Friedrichs Grängsjö, 2003). The product of the tourism sector is an experience that is delivered by a destination to its visitors. This experience is produced not by a single firm but by all players, which impact the visitor experience. The multiplicity of players involved in the supply and delivery of tourism services, and therefore the experience of the visitor, makes management of the destination product vastly more complex compared to the management of most simple products produced by single firms (Crouch, 2007).

Since individual firms have no control over the path the tourist takes through a destination, the product only exists when the tourist activates that particular combination, or network of services (Gnoth, 20O2). This provides a number of challenges from a supply point of view, because the individual operators are not able to control the service delivery of the entire experience (Ritchie and Crouch, 2003; Von Friedrichs Grängsjö, 2003). Travel plan usually consists of several stages, such as the election of destination, selection of tourist attraction, accommodation choice, the decision about the route and so on. In order to recommend satisfactory tourist attractions to travelers the characteristics of tourist attractions, for example the activities offered in an attraction, have to match travelers' preferences (Huang, Bian, 2009). However, travel preferences are often hidden and are not explicitly known when users start to plan their trips, particularly if visiting an unfamiliar place (Viappiani, et al., 20O2). In order to build an efficient user model, we have to consider tourists' preferences, to estimate them and made appropriate conclusions.

The issue of what attracts tourists mostly in choosing certain destinations or certain forms of tourism is considered for years. So, if we want to get this answer we must take in consideration some models that would be helpful for solving this problem. In order to define the attributes that largely determine a tourist destination we took two models. The first possible approach, Bayesian approach, recognizes the fact that, at least to some extent, the collective 
experience, knowledge, and insights of tourism destination managers, researchers and others who have spent time addressing the challenge of what makes a destination competitive, can provide a useful starting point for an analysis such as this (Crouch, 2007). This Bayesian approach to estimation and inference implies that additional information can be used to reduce uncertainty and improve knowledge (Griffiths, Hill, Judge 1993). Modern application of Bayesian methods is primarily reflected in the implementation of Bayesian networks. Bayesian networks provide a method for representing relationships between variables (called 'nodes' in the BN) even if the relationships involve uncertainty. They can be a useful modeling tool in situations where different types of variables and knowledge from various sources need to be integrated within a single framework (Pearl, I988; Jensen, I996).

A Bayesian network is used to estimate the traveler's preferred activities. With the Bayesian network, travel behavior of the person and of other travelers who have similar taste can be combined (Huang, Bian, 2009). These networks have proven to be very useful in solving complex problems, identifying key variables and defining events that have the greatest likelihood of realization, so that is the reason why the authors of this paper have chosen the Bayesian network for predicting tourists' preferences.

Application of second approach, the AHP model, has to highlight the aspects of using this model as a qualitative technique that is based on the evaluation and experience of decision makers in evaluating information in order to reach better decisions (Srdević, 2002). Moutinho, Rita and Curry (I996) and Curry and Moutinho (1992) have examined the application of such methods in a tourism context and have identified the advantages of the Analytic Hierarchy Process (Crouch, 2007). The decisions which face tourism planners typically involve variables which are difficult to measure directly and even if all variables can be measured accurately there are still severe problems to be faced in obtaining numeric measures of the relative importance of decision variables. The AHP was designed as an all purpose method for achieving these aims (Moutinho, Rita, Curry, I996). The use of expert system techniques is not completely new in tourism marketing (Mazanec, I990; Moutinho, Rita and Curry, I996; Wöber, 1999). Nowadays, the application of different techniques is usual, and AHP model is technique that could help decisions makers in preparing good decisions. Application of this model is not always easy; first of all, we need the expert knowledge and experience, good choice of criterions and sub criterions that affect on alternatives, and appropriate software to make calculations easier. Software that supports this model is EC2OOO, applied in Serbia in area of water resources, forestry, selection of plants, etc. With the current issue as a base, our aim is to deeply research application of this model in touristic area. We started with hypothetical example, explained basic notes and came to the conclusion that this is a field that could be very good starting point for the future work.

\section{Methods and data}

The research aim was the identification the attributes that had influence on tourist attraction and preferences. There are many tools and models that can be useful in this research area, but authors have chosen two the most appropriate: Bayesian network and AHP model. First step is to develop Bayesian network based on the empirical data that existed in the literature in travel domain. The prior and posterior probabilities, also based on known research, are shown through graphical examples. Bayesian networks have been used to perform a variety of predictive tasks, so we also used it for prediction travelers' behavior (Huang, Bian, 
2009). The second step is facing with decision making problem: tourist attraction depends on many factors that could be presented as set of decision criteria. Corresponding method that deals with these problems is the analytic hierarchy process. Defining the importance of the attributes of preferences may be the hardest part, so the results of the AHP have to be further analyzed to produce measures of attribute impact. Constructing AHP model is only the beginning of future research with relevant domestic data and, also, the part of decision making process about tourists' preferences in our region.

\section{The basic concept of Bayesian network}

Decision making entails a certain type of risk, because it often must occur in conditions where there is not enough available data or knowledge. This is in fact a decision making under uncertainty, where the available data and information can be quantitative or qualitative, linguistic or graphic display. Such types of information are usually vague and ambiguous, but even so are important evidence for making decisions under uncertainty. In the absence of accurate data, expert opinion is an integral part of decision making process.

Bayesian network models are one method for combining scientific data with expert knowledge and experience (Marcot et al., 2006). It is a tool that can be used to build a decision support system, and these are increasingly being used to model uncertain and complex systems (Uusitalo, 2007). Bayesian networks were originally developed to allow the impact of uncertainty about management systems to be accounted for in the decision making process (Cain, 2OOI). These models are comprised of three elements:

I. A set of nodes representing the system key variables,

2. A set of links that represent the cause effect relationship (conditional dependence) between the nodes,

3. A set of probabilities representing the belief that a node will be in a given state given the states of the connecting nodes (Shenton et al., 2007).

These conditional probability relationships may be based on any available information, including experimental or field results, process-based model outputs, or the carefully elicited judgment (beliefs) of experts (Borsuk et al., 2006).

\section{Estimating tourists’ preferences using Bayesian network}

Main task, in this part of paper, was to estimate tourists' preferred activities based on the Bayesian network. With that intention, we took into account the empirical data that existed in the travel literature. In the origin paper (Huang, Bian, 2009), the authors wanted to determine what attracts tourists mostly in the selection of specific destinations, namely New York City and Niagara Falls. For the study, they examine 200 tourism websites and display the results of its analysis through the Bayesian network. The derived conclusions are presented through the next overview in several steps.

The first step involved defining the relevant variables and the relationships between them (Figure I). The variables in the Bayesian network contain a set of factors influencing the preferred activities that are common mentioned by researchers in travel domain. 


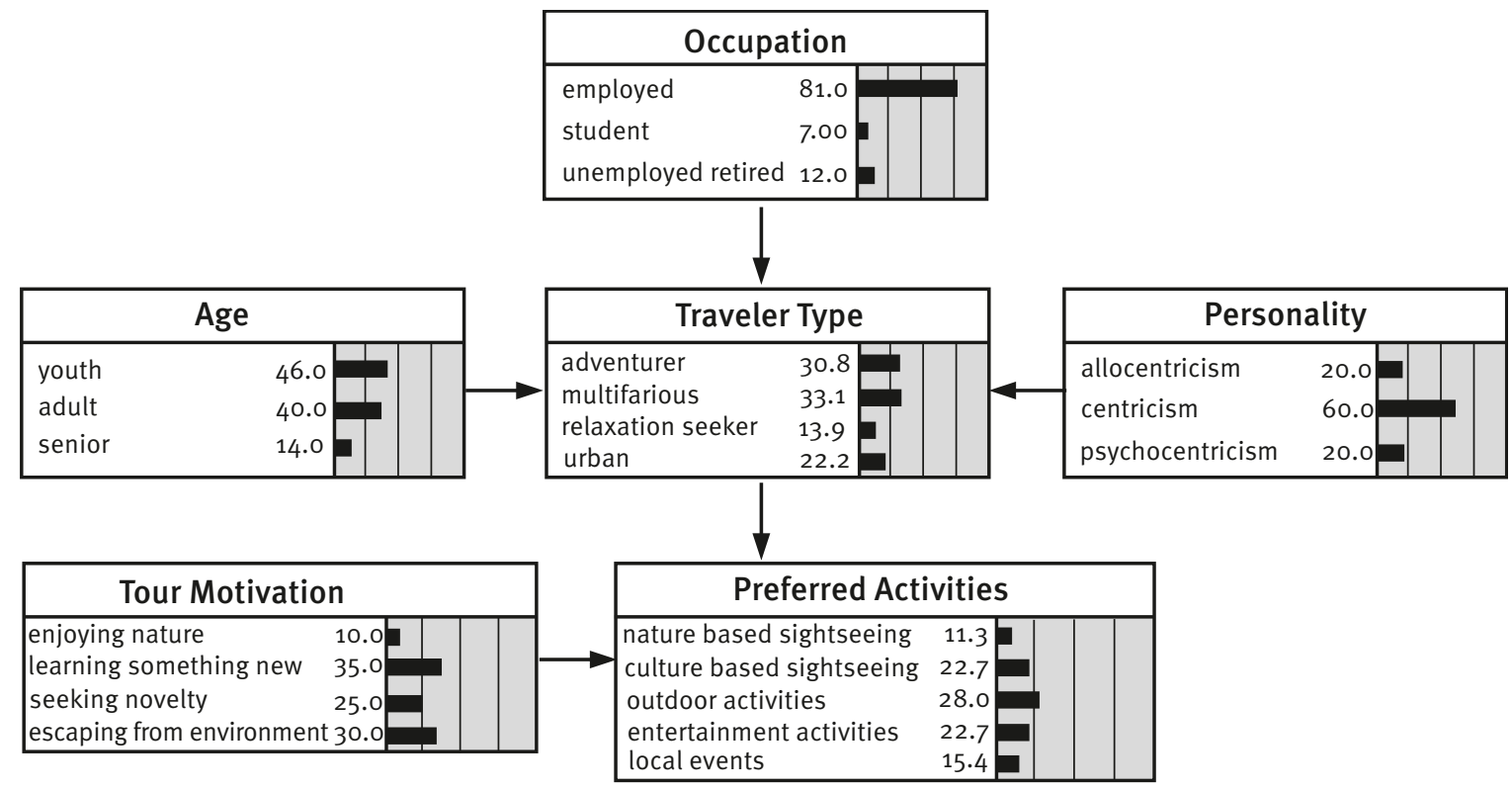

Figure 1. The prior probability distributions

Source: Huang, Bian, 2009

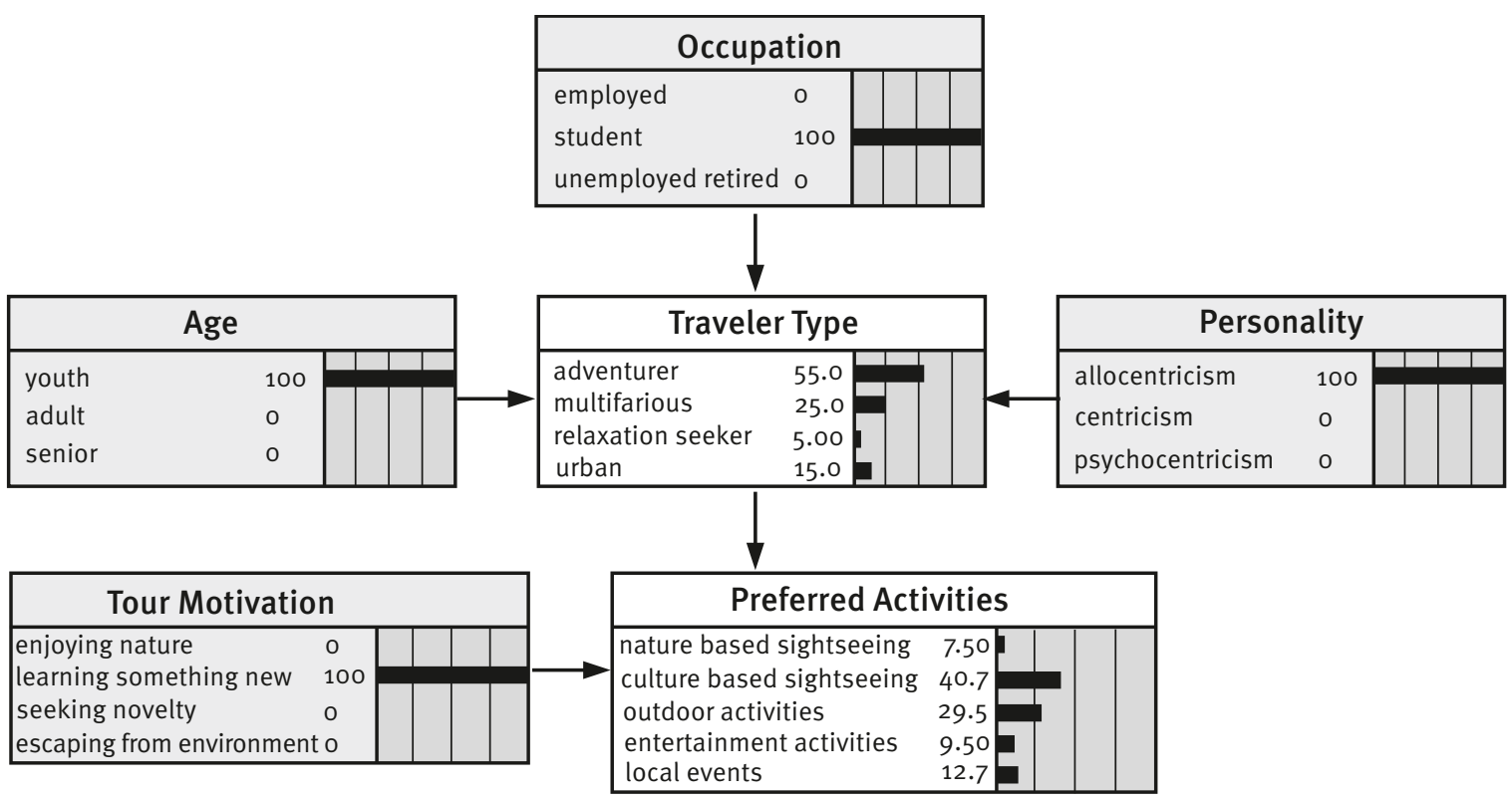

Figure 2. The posterior probability distributions

Source: Huang, Bian, 2009

Nodes without parents, also called root nodes, are respectively: Occupation, Age, Personality and Tour Motivation. Three variables affect on Traveler Type and these variables in combination with Tour Motivation have its influence on the Preferred Activities. So, if the probability distribution of any parent node is changed it could cause the change of Traveler Type 
probability and, consequently, the change of probability distribution of Preferred Activities. The probability distributions for Traveler Type and Preferred Activities are calculated using Bayes theorem.

Bayesian estimation is based on prior probability distribution, but it could be updated using available information. In this way it can be obtained posterior probability distribution (Figure 2).

In the light of new information based on the person's personal info (tourist is a young person, his (her) occupation is studies and personality is allocentric) and probability distribution of Traveler Type, we can estimate Preferred Activities using appropriate software. The highest calculated probability has activity "culture based sightseeing" (4O,7\%), so we can conclude that this profile of tourists that activity attracts mostly in choosing a specific destination.

This kind of estimation combines social factors and tour characteristics. To get a clear view of tourists' preferences, estimation was based on the travel behavior of tourists. The conditional probability is assigned based on the existed survey. But in reality, users preferences depend heavily on the decision context and are often unknown in the beginning, ill specified, and incomplete. If asked, people often state some criteria to be very important, but prefer others when more decision criteria emerge later on (Viappiani, et al., 2OO2). With that in mind, we go further seeking for another model that involves structuring several choice criteria into a hierarchy, assessing the relative importance of these criteria, comparing alternatives for each criterion, and determining an overall ranking of the alternatives.

\section{Analytic hierarchy process - general remarks}

The Analytic Hierarchy Process (AHP) is very useful in analyzing complex decision problems, because it organizes the decision problem as a hierarchical structure containing always several levels. The first (topmost) level defines a main goal of the decision problem and the last (lowest) level describes usually the decision alternatives or scenarios. The levels between the first and the last level can contain secondary goals, criteria and sub criteria of the decision problem. The number of the levels is not limited, but in the typical case it does not exceed four or five (Jablonsky, 2005). The elements of intermediate levels are weighted. Namely, each element on a level is evaluated about the elements, i.e. criteria, on the immediately above level to acquire relative weights $\left(w_{i}\right)$ of the elements on the same level.

The weight of the entire hierarchy is acquired using the weights of the elements on each level. According to the weight, priority of each alternative for the overall objective is acquired (Kinoshita, Nakanishi, I999).

In the standard AHP model the decision maker judgments are organized into paired comparison matrices at each level of the hierarchy. The judgments are point estimates of the preference between two elements of the level. Saaty (I990) proposes to use for preference expression $a_{i j}$ integers in the range I through 9 , where I means that the $i$-th and the $j$-th element are equally important and 9 means that the $i$-th element is absolutely more important than the $j$-th element.

The decision maker always specifies point estimates that express his preference relations between two elements in the given hierarchical level. It can often be very difficult to fulfill this condition for decision makers. They feel much better and closer to have the possibility to express their preferences as interval estimates. For instance, instead of giving that the $i$-th 
element is four times as preferable as the $j$-th element, he can assert that the $i$-th element is at least two but no more than five times as preferable as the $j$-th element (Jablonsky, 2005).

\section{Application of AHP model for ranking tourists' preferences}

The AHP model is widely adopted in various fields such as economic problems, management problems, energy problems, a policy decision and city planning. AHP model can also be successfully applied in tourism, for solving tourist attraction problem. In general, using the AHP in this area include four stages: (I) constructing a decision matrix including the value of each criterion for each alternative; (2) constructing a comparison pair wise matrix of the criteria; (3) deriving the relative weight of the criteria from the comparison pair wise matrix; and (4) computing the rank of each alternative based on the derived relative weight (Cheung, et al., 2OOI).

Specific forms of tourism, which among others include the business, cultural and rural tourism, require specific facilities, services, products, in a word, specific tourist destination. The strategy of positioning a tourist destination for these types of tourist movements must start with the fact that competition is strong and travel needs very heterogeneous. The process should begin by selecting the market in which we want to promote and place our tourist destination (Štetić, 2007). This leads to the question that opens up the need for constructing analytic hierarchy process, which is related to the attributes of tourist destination that should be used to distinguish it from other destinations. Promotion of tourist destinations and its representative attributes are increasingly emphasizes the role of marketing in tourism, so the AHP model can help us to indentify those attributes and to apply them on hypothetical example.

Based on the above Bayesian network, we decided to create AHP model in order to evaluate tourists' satisfaction. Our inspiration was the article made by Yuxia Huang and Ling

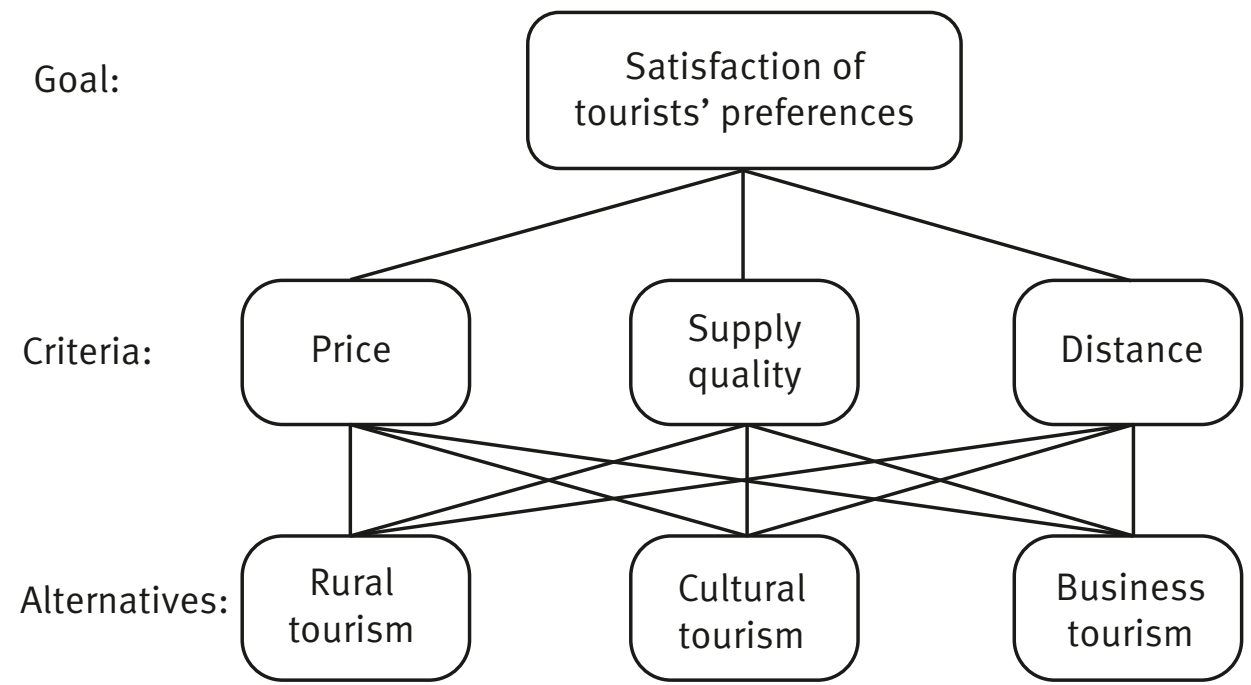

Figure 3. AHP model for evaluation tourists' satisfaction 
Bian with only theoretical implications, and the papers of Bojan Srđević who already applied this model in different research areas in Serbia.

Our aim was to create a base for future research and to see how it can work, first with the assumed data and later, in future work, with real data collected in the city of Novi Sad. Hence, the following example is hypothetical and is not related to the real tourist's interests in the observed area. While thus, it lost its importance, but it can serve as a basis for identifying the advantages of this method, especially in the work of travel agencies. The applied model, supported by appropriate software, could greatly facilitate the work of tour operators in the selection of touristic destinations that can satisfy tourists' preferences.

If we consider tourists' interests in the region of Vojvodina, we could distinguish three alternatives: Rural tourism, Cultural tourism and Business tourism. These forms of tourism were taken as a representative touristic products. The reason for this is that these three forms tend to become a bright spot for tourism development in Vojvodina. Our goal was to satisfied tourists' preferences if we identify criteria as the relevant factors. These factors include the Price of corresponding arrangement, satisfaction with Supply quality and the Location of the attraction. Figure 3 shows the AHP hierarchy for this decision problem.

In the decision making process with AHP, there is a need for determining priorities for the alternatives with respect to each decision criteria, and priorities for each criterion with respect to their importance in reaching the goal.

\section{Criteria and alternatives comparison}

The concept of the method is to be the rational and intuitive in the same time, and also to determine the best among several alternatives, in a consistent framework of the alternatives evaluation, in relation to a given set of criteria, sub criteria, etc. During the process, the decision maker performed only basic comparisons in pairs, and AHP model integrate it to the level of defining weight values and the ranking (Srđević, 2002).

In this part of paper we assume that tourists would prefer to visit popular attractions in the region of Vojvodina and if one attraction is not promoted quite often, we considered it like unpopular. Using Saatys' fundamental scale in assigning the weights, we get the comparison matrix.

In Saatys' approach the decision-maker need to express his opinion about the value of one comparison pair. There is a set of discrete choices, each choice is language phrase such as " $\mathrm{A}$ is more important than B", "A has the same importance as B" or "A is little more important than B" and so on (Srdević, 2002).

To properly performed comparisons, it is necessary to consult experts in the observed field to make each matrix precisely defined. Based on that, already at the beginning it can be concluded that the applied AHP model represents a synthesis of expert knowledge and their prior experience, so an element of subjectivity could be a potential weakness of this method.

The first step in AHP model is the comparison of each criterion and the calculation of their relative weight with respect to their importance in reaching the goal (Table I). This part of the process requires much discussion and debate among the decision makers and in our example it is the result of authors' subjective assessment.

Application of AHP model showed that the largest weight coefficient has the price of corresponding arrangement (0.658), so we can conclude that the Price is the most relevant criterion in choosing type of touristic attraction. 
Table 1. Comparison matrix for criterions

\begin{tabular}{|l|c|c|c|c|c|}
\hline Criteria & Price & Supply quality & Distance & Priority (wi) & Rank \\
\hline Price & 1 & 5 & 7 & 0.658 & 1 \\
\hline Supply quality & $1 / 5$ & 1 & 9 & 0.281 & 2 \\
\hline Distance & $1 / 7$ & $1 / 9$ & 1 & 0.061 & 3 \\
\hline \multicolumn{7}{|r}{} \\
\cline { 2 - 5 }
\end{tabular}

Table 2. Comparison matrix with respect to price

\begin{tabular}{|l|c|c|c|c|}
\hline PRICE & Rural tourism & Cultural tourism & Business tourism & Priority (wi) \\
\hline Rural tourism & 1 & $1 / 7$ & $1 / 9$ & 0.057 \\
\hline Cultural tourism & 7 & 1 & $1 / 3$ & 0.294 \\
\hline Business tourism & 9 & 3 & 1 & 0.649 \\
\hline \multicolumn{4}{|r|}{} & \\
\hline
\end{tabular}

Table 3. Comparison matrix with respect to supply quality

\begin{tabular}{|l|c|c|c|c|}
\hline SUPPLY QUALITY & Rural tourism & Cultural tourism & Business tourism & Priority (wi) \\
\hline Rural tourism & 1 & $1 / 9$ & $1 / 9$ & 0.052 \\
\hline Cultural tourism & 9 & 1 & 1 & 0.474 \\
\hline Business tourism & 9 & 1 & 1 & 0.474 \\
\hline \multicolumn{7}{|r|}{} & & 1.000 \\
\hline
\end{tabular}

Table 4. Comparison matrix with respect to distance

\begin{tabular}{|l|c|c|c|c|}
\hline DISTANCE & Rural tourism & Cultural tourism & Business tourism & Priority $\left(w_{i}\right)$ \\
\hline Rural tourism & 1 & $1 / 9$ & $1 / 9$ & 0.052 \\
\hline Cultural tourism & 9 & 1 & 3 & 0.632 \\
\hline Business tourism & 9 & $1 / 3$ & 1 & 0.316 \\
\hline \multicolumn{5}{|r|}{} \\
\cline { 2 - 4 }
\end{tabular}

Table 5. Weighting coefficients of alternatives with respect to goal

\begin{tabular}{|c|c|c|c|c|c|}
\hline & Price & Supply quality & Distance & Priority $\left(w_{i}\right)$ & Rank \\
\hline Rural tourism & 0.038 & 0.015 & 0.003 & 0.056 & 3 \\
\hline Cultural tourism & 0.193 & 0.133 & 0.039 & 0.365 & 2 \\
\hline Business tourism & 0.427 & 0.133 & 0.019 & 0.579 & 1 \\
\hline Totals: & 0.658 & 0.281 & 0.061 & 1.000 & \\
\hline
\end{tabular}

In the next stage, we estimate each alternative, respectively Rural, Cultural and Business tourism, compared to every criterion. The three comparison matrix, dimensions $3 \times 3$, are defined and shown in Tables 2, 3 and 4. Rows and columns in the matrix correspond to the offered alternatives.

Table 2 presents the judgment matrix, where we can see that the Business tourism is the most sensitive on the criterion Price, because its weight coefficient is 0.649.

In the Table 3 is shown that the best Supply quality have two kind of tourism: Business and Cultural, because its weight coefficients are the same (0.474).

In the fourth table, Cultural tourism is presented as the closest one because, with respect to Distance, its weight coefficient is 0.632 . 
Now when we know the priorities of the criteria with respect to the goal, and the priorities of the alternatives with respect to the criteria, we can calculate the priorities of the alternatives with respect to the goal (Table 5). This is a straightforward matter of multiplying and adding, carried out over the whole of the hierarchy.

Table 5 contains the final results of applied AHP method. Of three considered alternatives, according to given criteria, the tourists are the most satisfied with Business tourism, because it takes 57.9 percent from total. On the second place is Cultural tourism (36.5\%) and on the last, third place is Rural tourism with only 5.6\%.

As a measure of the results reliability, usually is used a calculating procedure that weigh consistency degree of evaluation process. An appropriate degree is accepted as a satisfactory if each value is less than O.IO (Saaty, I980; Stoiljković, Srđević, Veljković, 2006). With intention to estimate the consistency, we used formula:

$$
\mathrm{CR}=\mathrm{CI} \div \mathrm{RI}
$$

Where $C R$ is the consistency degree, $C I$ is the consistency index and $R I$ is the random index. In our example, $C R$ or consistency degree, for comparison matrix for three different criterions (Table 2, Table 3 and Table 4) are respectively: 0.068 for criteria Price, 0.002 for criteria Supply quality and O.II for the last criteria, Distance. First two are less then accepted limit (O.IO) and only the last one is little higher, but it is also acceptable. So we can say that the consistency degree is appropriate and it could be said that the results are reliable.

\section{Conclusion and further implications}

Among the multicriteria methods, analytic hierarchy process takes very important place, so the presented model could be used as a valuable support for decision making in tourist area. The aim of the paper was to verify how the AHP model can be used in ranking tourist attractions and the results provided an insight into the attributes of tourists' preferences. Applying this method we got that Business tourism attracts mostly, because its weight coefficient is highest one (0.579). In combination with presented Bayesian network it could be a useful framework for managing tourism competitiveness.

Of course, the choice of criterions might be different, but we left that for future research. Coupled with the results of this current study, there is now some evidence that would help us to indentify what factors may be more important or influential than others. This information can therefore serve as a guideline for improvement destination performance.

The objective of this study was primarily focused on the appropriate methodology that could be used in the touristic area. The current example from the literature has indicated the possibility of applying Bayesian network in domestic circumstances. If the surveys conducted in the area of Novi Sad, the results could be shown through Bayesian network. In this way we would come to the information what attracts tourists' mostly in choosing particular destination.

On the other hand, the analytic hierarchy process can help in solving so-called "unsolved problems". As mentioned above, the strength of preferences may vary. In the case where two or more destinations have many common characteristics, such as accommodation conditions, food quality, the attractiveness of offered services, price, etc., the decision maker, i.e. inter- 
viewed tourist, can be found at practically insoluble dilemma. But, by applying the AHP model and Saatys' scale for comparison in pairs, responses, however, may occur.

Application of this model by travel agents and agencies would enable easier selection of tourist destinations that would greatly suit the needs of clients. Hence, the promotion of appropriate travel arrangements selected by using the AHP method, save time and money, and as a result of the process followed the client's satisfaction with the offered destinations. The authors' idea is to confirm the theoretical implications on the data collected from the area of Novi Sad, and thus further strengthen the relationship between marketing tourism and application of analytic hierarchy process methodology in practice.

\section{References}

Borsuk, M.E., Reichert, P., Peter, A., Schager E., Burkhardt-Holm P. (2O06): Assessing the decline of brown trout (Salmo trutta) in Swiss rivers using a Bayesian probability network, Ecological Modelling 192, 224-244.

Cain, J. (2OOI): Planning Improvements in Natural Resources Management, Centre for Ecology and Hydrology, Wallingford, Oxfordshire, UK.

Cheung, S., Lam, T., Leung, M., Wan, Y. (2OOI): An analytical hierarchy process based procurement selection method, Construction Management and Economics I9(4), 427-437.

Crouch, J. (2007): Modeling destination competitiveness: A survey and analysis of the impact of competitiveness attributes, CRC for Sustainable Tourism Pty Ltd, Queenslend.

Curry, B., Moutinho, L. (I992): Environmental Issue in Tourism Management: Computer Modelling for Judgemental Decisions, International Journal of Service Industry Management 3(I), 57-69.

Gnoth, J. (20O2): Consumer activated networks: towards a dynamic model for tourism destinations, Marketing Networks in a Global Economy, Monash University, Kuala Lumpur.

Griffiths, W.E., Carter Hill, R., Judge G.G. (I993): Learning and Practising Econometrics, John Wiley \& Sons, Inc., New York.

Huang, Y., Bian, L. (2009): A Bayesian network and analytic hierarchy process based personalized recommendations for tourist attractions over the Internet, Expert Systems with Applications 36, 933-943.

Jablonsky, J. (2005): Measuring efficiency of production units by AHP models, ISAHP, Honolulu, Hawaii.

Jensen, F.V. (I996): An introduction to Bayesian networks, Springer, New York.

Kinoshita, E., Nakanishi, M. (I999): Proposal of new AHP model in light of dominant relationship among alternatives, Journal of the Operations Research Society of Japan 42 (2), I8OI98.

Kotler, Ph., Keller, K.L. (2006): Marketing Management, Data Status, Belgrade.

Marcot, B.G, Stevenson, J.D., Sutherland, G.D., McCann, R.K. (2006): Guidelines for Developing and Updating Bayesian Belief Networks Applied to Ecological Modeling and Conservation, Canadian Journal for Forestry Research 36, 3063-3074.

Moutinho, L., Rita, P., Curry, B. (I996): Expert Systems in Tourism Marketing, Routledge, London.

Pearl, J. (1988): Probabilistic reasoning in intelligent systems: networks of plausible inference, MorganKaufmann Publishers, San Mateo, California. 
Ritchie, J.R.B., Crouch, G.I. (2OO3): The competitive destination: a sustainable tourism perspective, CABI, Wallingford, U.K.

Saaty, T.L. (I990): The Analytic Hierarchy Process, RWS Publications, Pittsburgh.

Shenton, W., Hart, B.T., Brodie, J. (2007): Development of a Bayesian Network Model for Linking Management Actions, Nutrient Targets and Ecosystem Condition in the Tully Catchment, North Queensland LWA/MDBC Project UMO43.

Srdević B. (2OO2): Decision-making using the Analytic hierarchy process, Melioration and Agriculture, Faculty of Agriculture, Novi Sad, 2O4-22I.

Stojiljković M., Srđevic B., Veljković V. (2006): Selection procedures for filtration of waste water emulsions using Analytic Hierarchy Process, Melioration - soil and water, Faculty of Agriculture, Novi Sad, 94-IOI.

Štetić, S., (2007): Special forms of tourism, Forma B, Belgrade

Uusitalo, L. (2007): Advantages and challenges of Bayesian networks in environmental modeling, Ecological Modelling 2O3, 3I2-3I8.

Vasiljev, S. (2005): Marketing, Prometej, Novi Sad.

Viappiani, V., Pu, P., Faltings, B. (20O2): Acquiring user preferences for personal agents, In Proceedings of the AAAI fall symposium, 53-59.A

Von Friedrichs Grängsjö, Y. (2OO3): Destination Networking: Co-opetition in peripheral surroundings. International Journal of Distribution and Logistics Management 33 (5), 427448.

Wöber, K.W. (I999): Standardizing city tourism statistics, Annals of Tourism Research 27(I), 5I-68, Elsevier Science Ltd. 